\title{
O longo processo histórico de consolidação da "Macro-Região Canavieira Paulista"
}

\author{
Mateus de Almeida Prado Sampaio ${ }^{1}$
}

mapas@usp.br

Resumo: Este artigo reflete, ainda que de forma limitada, acerca da cana-deaçúcar (Saccharum officinarum) no Estado de São Paulo. Seu foco é, a princípio, sugerir uma proposta de regionalização para tal cultivo agrícola, levando em conta a indissociável relação tempo-espaço. Trata-se, de certa forma, de um esboço de geografia histórica. Nesse breve traçado apontado para a atividade canavieira no Estado, predominará uma visão geográfica. A não padronização e uniformização dos mapas indicam se tratar de uma pesquisa ainda em andamento.

Palavras-Chave: Cana-de-açúcar; Estado de São Paulo; Geografia Histórica; Regionalização

Abstract: This article reflects the sugarcane (Saccharum officinarum) in São Paulo state. Its focus is, in principle, suggest a regionalization proposal for this crop, taking into account the inseparable relationship between time and space. This is an outline of a kind of historical geography. In this brief historical route pointed the sugarcane industry in the state, will predominate a geographic perspective. The lack of standardization and uniformity of the maps indicate that this a study still in progress.

Key words: Sugarcane, State of São Paulo; Historical Geography; Regionalisation

\section{Introdução}

Como resumir os aproximadamente 480 anos de produção açucareira e 220 anos de comercialização com o mercado internacional em poucos parágrafos, e sem muita repetição do que já se escreveu? Impossível... Tentaremos exercer a atividade de síntese, o que nos reduzirá os pormenores, porém possibilitará uma idéia mais "enxuta" das principais fases canavieiras paulistas. Os subitens a seguir virão periodicizados. A consolidação de uma "macroregião" é nossa tese.

\section{De São Vicente à Itu; de Itu à Santos: 1534-1846}

Atribui-se a plantação das primeiras mudas de cana-de-açúcar - trazidas da Ilha da Madeira - na "América Portuguesa", à Martim Afonso de Sousa, primeiro donatário da capitania de São Vicente (raiz litorânea do que viria a ser São Paulo). Seu sucesso foi medíocre, porém não nulo. A poucos metros de onde hoje se localiza a Universidade de São Paulo (Cidade Universitária/Campus Butantã), Afonso Sardinha, já "em 1607, mantinha em 
sua fazenda de Ubatatá [Butantã], junto ao rio Jurubatuba [Pinheiros], um trapiche de açúcar, de que pagava grandes direitos ao Rei". ${ }^{2}$

Até a restauração da Capitania em 1765, seguida pela administração do Morgado de Mateus, sua produção canavieira era pequena, e sua função mercantil ainda menor. Aspectos internos e externos à colônia passavam por profundas mudanças em fins do XVIII. A atividade mineradora minguava, 0 comércio inter-capitanias arrefecia-se. Concomitantemente, a "Revolução Haitiana" havia aberto uma brecha de $30 \%$ no total demandado pelo mercado internacional de açúcar, o que estimulou sobremaneira os primórdios dos contratos de compra e venda de mercadorias futuras na agricultura. ${ }^{3}$ As "Reformas Pombalinas" esforçavam-se por estimular a agricultura e o comércio em São Paulo, e o Tenente-general José Arouche Toledo Rendon pronunciavase, em 1788, contra a preguiça e a indolência dos roceiros da capitania, que "despidos daquela bem regulada ambição que faz florescer os Estados e impelle os homens ao trabalho e às indústrias" 4 fazia com que o "lavrador paulista apenas trabalha[sse] no ano dois a três meses [... estando] mais animados do espírito pela caninha que do amor ao trabalho". " A essa idéia contra-argumentou Antonio Candido de Mello e Souza, para quem isso "não deve ser considerado vadiagem, mas desnecessidade de trabalhar [...] plantava-se para viver, com pouca ou nenhuma utilização comercial do produto". 6

Na virada do século XVIII para o XIX a São Paulo canavieira subdividia-se, grosso modo, em duas regiões distintas: o "Litoral" e "Serra Acima". 7 "Serra Acima", sobretudo após o fortalecimento da atividade canavieira ituana, cindiuse novamente em duas áreas: o "Vale do Paraíba" e o "Oeste", na qual a vila de Itu era o principal centro agrícola. Estava iniciada a fase manufatureira dos grandes engenhos paulistas, que estimulou uma intensa anexação fundiária à sua lógica produtiva, assim como a fundação de novas vilas na capitania, que já estava prestes a se converter em "Província". Em 1797, "com o título de São Carlos, em comemoração do Augusto Nome da Rainha, a Senhora D. Carlota Joaquina", ${ }^{8}$ eleva-se a condição de vila Campinas. Em 1821 foi a vez de "Vila Nova da Constituição" se elevar, dando origem a Piracicaba. Firmava-se o "Quadrilátero do Açúcar", delimitado por Sorocaba, Jundiaí, Mogi-Mirim e Piracicaba. Seu centro fora Itu, principal lócus de expansão demográfica e canavieira do "Sertão" paulista, epicentro escravista e açucareiro. A categoria de senhores de engenho crescia em são Paulo na mesma medida em que se concentrava territorialmente: somavam 405 em 1798 e já eram 577 em 1828; e o "oeste", que detinha $37 \%$ dos senhores de engenho paulistas na primeira data e passa a abrigar $67 \%$ do total destes trinta anos mais tarde. ${ }^{9}$

"Em 1826 [...] Santos estava se transformando em porto internacional. Nesse ano, o total de açúcar exportado foi de 154.155 arrobas, sendo que o Rio de Janeiro recebeu somente 22.244 arrobas. Portos europeus, como Trieste, Gotenburgo, Antuérpia, Lisboa e o Porto, absorveram grande parte do açúcar exportado - 67.739 arrobas. O maior importador de açúcar paulista foi o porto de Montevidéu: 26.190 arrobas. Outro porto sul-americano, Valparaizo, com 
uma importação de 7.024 arrobas, merece ser mencionado. Os da América do Norte, Boston e Nova York, receberam 18.958 arrobas [...] Santos, muito antes de ser o porto do café, foi o porto do açúcar". ${ }^{10}$

A safra de 1846/47, quando foram exportadas quase 600.000 arrobas de açúcar por Santos, representou o auge da produção paulista durante a fase do "Quadrilátero". Ao longo da primeira metade do século este fora o principal artigo da capitania/província. Mas em pouco tempo a situação já seria outra. "De fato, notamos a nítida liderança do café sobre o açúcar na exportação santista a partir de meados da década de 1850". "11 "Ficou mantida apenas uma reduzida produção de açúcar e de aguardente, voltados ambos ao consumo local, e já na década de 1860 era necessário importar açúcar" para São Paulo. 12

\section{De Piracicaba espalha-se... 1875-1939}

O surto cafeeiro, dominador da economia nacional e ofuscador da marcha pioneira açucareira que havia ocorrido no interior paulista, confinou a área canavieira ao "Quadrilátero". Mesmo dentro deste, tomou o café boa quantidade das terras até então de cana. Exemplo da coexistência entre as duas culturas foi Piracicaba, que se manteve como importante produtor de ambas. Para além desse "primeiro oeste" representado pelo "quadrilátero", pulverizavam-se pela província (já agora em vias de se converter a "Estado") modestos engenhos de rapadura e de açúcar mascavo, assim como inúmeros alambiques de aguardente.

O setor açucareiro havia retraído, perdido sua importância relativa e sequer os estímulos oficiais concedidos a partir de 1875 para o estabelecimento dos "Engenhos Centrais" (sob os moldes dos instalados por ingleses, franceses e norte-americanos em Cuba, Guadalupe, Santa Lúcia e Martinica) surtiam o efeito esperado na tentativa de reerguer sua produção. Senhores, Doutores, Coronéis, Conselheiros, Barões e até Condes encontravam-se entre os cidadãos que se lançaram na empreitada de içar os Engenhos Centrais (ou melhor, foram os únicos que nela conseguiram se meter). Concretizaram-se apenas quatro empreendimentos (apesar de ter havido um número maior de projetos aprovados e beneficiados pelos incentivos oficiais): 1 no Vale do Paraíba (Lorena/1884) e 3 no antigo "quadrilátero": Porto Feliz (1877), Piracicaba (1882) e Raffard (1882). ${ }^{13}$ As falências foram generalizadas e a situação de "vai-não-val" se arrastou até a proclamação da república (1889), quando se abandonou a política oficial (que dava estímulos, mas exigia contrapartidas) e passou a predominar um sistema mais "liberal" que marcou o surgimento das primeiras "Usinas" no estado. Importante notar que o processo usineiro diferenciava-se de seu antecessor por não segregar as atividades de cultivo da terra das de fabricação industrial do açúcar, conformando-se assim como verdadeiras "agroindústrias". Os fundadores dessas usinas eram todos grandes fazendeiros de café ou comissários da rubiácea. Foram as quatro primeiras: Freitas (Araraquara/1889); Monte Alegre (Piracicaba/1896); Cachoeira (Franca/1896) e Indaiá (Franca/1898). 
O negócio açucareiro finalmente voltara a prosperar e atraía inclusive a atenção de grupos capitalistas internacionais. Quanto ao café, este beirava sua segunda grande crise de superprodução. Foi nesse contexto que em 1899 todos os três engenhos centrais estabelecidos no antigo "quadrilátero" - ou seja, os de Piracicaba, Raffard e Porto Feliz - foram comprados por uma firma de capital francês: a "Societé Française des Sucrérie Brésiliennes". O mesmo se passou com Engenho Central de Lorena, em 1901. Tal empresa francesa tornou-se, na virada do século, ao fazer uma associação com a "Dreyfus", a principal produtora e distribuidora de açúcar em São Paulo. Na corrente dos acontecimentos, vieram novas usinas: Pimentel (Jaboticabal/1903); London (Santa

do Viterbo/1904), Esther (Cosmópolis/1905) e Schmidt (Sertãozinho/1906). Arriscavam-se instalar fábricas em pleno "Planalto Ocidental Paulista". Ainda assim, São Paulo produzia apenas $22 \%$ do que consumia, "importando" os demais $78 \%$

"As empresas [açucareiras] estabelecidas em São Paulo não eram capazes de atender à crescente procura por seu produto. Por volta da transição do século XIX para o XX, o consumo do Estado girava em torno de 900 mil sacos de 60 quilos/ano. [...] Ora, as quatro usinas das Sociedades [Societé Française des Sucrérie Brésiliennes], trabalhando a todo vapor, poderiam produzir $150 \mathrm{mil}$ sacos. A estes pode-se acrescentar uns cinquenta mil produzidos pelas seguintes usinas situadas igualmente no Estado: Usina Santos-Dumont, Estação da Glória [London], 25 mil sacos; Usina de Monte Alegre, 15 mil sacos; Usina Franca de Augusto Ramos [Indaiá], 6 mil sacos; Usina Fortaleza [Freitas], 3 mil. Com o resto produzido por pequenos fazendeiros dispersos aqui e ai chega-se ao total de 200.000 sacos, que o Estado deve estar produzindo atualmente. O restante precisa ser importado das regiões de Campos [RJ] e de Pernambuco". ${ }^{14}$

O déficit açucareiro de São Paulo representava uma ótima possibilidade de negócio para aqueles dotados de capital e visão empresarial - eram-lhe, sobretudo, uma opção ao café, que sofria com as periódicas crises de superprodução e desvalorização. Tratava-se de uma forma investir ao mesmo tempo em dois mercados (opostos e complementares): o externo (com o café) e o interno (com o açúcar e a aguardente, voltados a uma população crescente via altas taxas de imigração). De forma mais discreta, assim como o café "marchou" pela "hinterlândia" do estado, também a cana o fez, seguindo-o de perto; e "quanto mais os cafezais se expandiam em São Paulo, mais prosperava a lavoura canavieira, as engenhocas e as usinas de açúcar". " 15 Foi nesse âmbito que Henrique Dumont e Francisco Schmidt, respectivamente tidos como o $1^{\circ}$ e o $2^{\circ}$ "Reis do café", firmaram-se como, sem dúvida, dois dos maiores usineiros de seu tempo. ${ }^{16} \mathrm{Em}$ relação às formas de trabalho, abandonara-se a escravidão e estabelecera-se o colonato açucareiro. Ficava para trás a aristocracia e iniciava-se a época da "burguesia industrial do açúcar". ${ }^{17}$ A modernidade reforçava sua presença na paisagem e na 
sociedade através de novos elementos técnicos (dos quais se destacavam as ferrovias, as moendas de aço e a energia a vapor) e de novos profissionais envolvidos, tais como Agrônomos, Químicos e Engenheiros. Firmavam-se "pontos açucareiros" dispersos pelo Estado e apenas a região de Piracicaba, "filha legítima" do "quadrilátero", já se encontrava conformada. Já no que se refere à cachaça, predominava uma intensa dispersão, com muitos pequenos produtores atuando no segmento:

"Se há municípios que não tenham engenhocas, o que é raríssimo, outros há que têm em grande número, como o de Pirassununga, que tem 125". 18 "Em Sertãosinho e Jardinópolis, onde se acham plantações de cannas destinadas à fabricação de aguardente, a cultura é toda rotineira, e não merece menção especial [...] Em Santa Bárbara e Villa Americana, porém, os americanos introduziram a cultura por meio de arados e outras machinas aratorias, e possuem as melhores mulas que pódem ser encontradas no Estado [...] É pena elles fabricarem só aguardente". ${ }^{19}$

Mesmo diante da predominância das engenhocas de açucares mascavos, rapaduras e, principalmente aguardentes, novas fábricas de açúcar surgiam "pipocando" 20 espalhadas sobre o território estadual, brotando nos ramais ferroviários interioranos mais agitados e dinâmicos, das quais destacaremos algumas. Em 1910, por exemplo, iniciam-se as atividades da usina Junqueira de Igarapava, "à boca do sertão", ${ }^{21}$ o que lhe conferia o quase monopólio dos mercados da Alta Paulista, Triângulo Mineiro e Goiás. Em 1911 foi a vez da Usina Itahyquara, em Tapiratiba, na região de Caconde, Ramal de Guaxupé da Mogiana. Em 1914 uma bem divulgada inauguração: a usina Santa Bárbara, da "Companhia de Estrada de Ferro e Agrícola de Santa Bárbara" - empresa dotada de alta monta de "capital realizado": mais precisamente "dous mil e quinhentos contos de réis, representado em 12.500 acções integradas e ao portador, do valor nominal de $200 \$$ cada uma, devidamente admittidas a cotação e negociações nas bolsas de S. Paulo e da Capital Federal'. 22 Parte considerável dos capitais e das tecnologias empregados nessa empresa eram de origem francesa; já havendo na fazenda adquirida para a construção da usina uma "Fábrica de Álcool" em funcionamento desde 1899. No entanto, em 1922 esta usina foi comprada por um cafeicultor da região de Ribeirão Preto, que promoveu-lhe grandes mudanças, projetando-a definitivamente entre as maiores do Estado. ${ }^{23}$ Tal negociata pode ser vista como um investimento trans-regional (se é que se pode falar assim), já que um capitalista da área core do café (Ribeirão Preto) colocou seu dinheiro e trabalho numa empresa localizada na área core do açúcar (eixo Piracicaba-Campinas). Ganhava com a maior proximidade da capital - que com o início da industrialização passava a demandar também álcool industrial - e com a elevada densidade ferroviária regional, com saídas para Piracicaba, Campinas e Rio Claro (e dessas duas últimas cidades abria-se um leque de outras localidades), todas consumidoras de açúcar. Ainda nesse mesmo contexto, criam-se as usinas "Albertina" (Sertãozinho/1916 - a segunda construída por Schmidt no mesmo município); "Miranda" (Pirajuí/1920: a primeira do "Novíssimo Oeste", na pioneira linha Noroeste 24. "Vassununga" (Santa Rita do Passa Quatro/1924), na estação 
terminal do ramal de Santa Rita da Companhia Paulista; e a "Itaquerê" (Nova Europa/1925), que era parte de um grande empreendimento misto (envolvendo café, pecuária, açúcar e colonização) e que contava com uma "ferrovia particular [...] ligada à Estrada de Ferro Araraquara, [ainda que localizada] em zona privilegiada da Cia. E. F. do Dourado". ${ }^{25}$ Por outro lado, a efêmera Usina Guatapará poucos anos ants, localizada em Ribeirão Preto, fundada pela poderosa Cia. Agrícola Guatapará, já em 1924 encerrara seu breve ciclo de atividades. Igarapava, Sertãozinho e Caconde se configuravam como as "zonas cannavieiras mais novas". ${ }^{26}$

Economicamente, a importância relativa da cana frente ao café era crescente; assim como o era a do açúcar em relação à aguardente. Mesmo intensificandose a participação de grandes fazendeiros e de capitalistas (nacionais e estrangeiros) na produção canavieira paulista, o que predominou amplamente até 1920 foi a produção de aguardente sobre a de açúcares; assim como de açúcares mascavos e rapaduras sobre o produto industrialmente refinado. ${ }^{27}$ Espacialmente despontavam outras avançadas usinas no interior oeste paulista: a "Lambari" (em Jaú) e a "Paredão" (em Marília) - ambas datadas da segunda metade da década de 1930. Em direção oposta, nos contrafortes da Mantiqueira surgia a usina "Nossa Senhora Aparecida" (Itapira/1930). No Vale do Paraíba, o Engenho Central de Lorena fechava suas portas (1933), tirando essa região definitivamente do grande circuito produtivo açucareiro paulista.

Se grandes fazendeiros e capitalistas eram os donos das grandes e modernas fábricas de açúcar, as engenhocas e os alambiques estavam nas mãos de pessoas (ou melhor, famílias) menos capitalizadas, mas bastante batalhadoras. A expansão demográfica e a dinâmica das frentes pioneiras do Estado possibilitavam que outro tipo de "ator social" entrasse em cena na economia canavieira paulista. Eram os imigrantes, muitos dos quais ex-colonos tornados sitiantes. Em sua maioria eram italianos. Destacaremos como elucidativos desse contexto a participação de três Pedros, que se não representam exatamente uma "regra" ou "modelo" de ascensão social, também não deixam de ser indicadores das transformações em curso na canavicultura paulista. São estes, os Pedros Morganti, Biagi e Ometto. Morganti representava a mentalidade do industrial. Sendo um homem urbano, montou em 1902 um primitivo (em inventivo) sistema de refinação artesanal de açúcar. Fez isso no pequeno cômodo sem janela em que morava na Vila Buarque (capital). Tal façanha lhe permitiu ganhar dinheiro, mas tanto dinheiro, que na década de 1950 ele detinha a maior e mais moderna usina açucareira da América do Sul (a Tamoio, que nada mais era que a usina Freitas, posteriormente convertida em Fortaleza e finalmente batizada com o sugestivo nome: TAMOIO). Morganti havia anteriormente comprado a Monte Alegre, configurando-se como primeiro exemplo de usineiro operante concomitantemente em duas regiões canavieiras paulistas: a consolidada região piracicabana e a araraquarense, ainda em fase incipiente de formação. Biagi era bom comerciante, trabalhava com produção e distribuição de tijolos, telhas, lenha, dormentes e aguardente em Pontal, um pequeno povoado perto de Ribeirão Preto. Um forte temporal ocorrido em 1896 danificou grande parte das residências da região, possibilitando boa margem 
de lucro ao vender seus "stocks". Com persistência alcançou fortuna e montou, a partir do zero, três usinas: Barbacena (Pontal/1918), Da Pedra (Serrana/1931) e Santa Elisa (Sertãozinho/1936). Juntamente com as duas grandes usinas de Schmidt localizadas em Sertãozinho, e com a mais modesta usina São Vicente (Pitangueiras/1931), de seu cunhado João Marchesi, reforçou o processo de formação da "área de Pontal-Sertãozinho-Pitangueiras". 28 Ometto cedo havia ficado órfão de pai, e Caterina, a matriarca, ao ficar precocemente viúva ainda era colona numa fazenda piracicabana de café. Eram uma família de agricultores, composta por muitos filhos, que com bastante trabalho, conseguiram, pouco a pouco, comprar alguns módicos hectares de terras na região. Montaram um engenho para destilar aguardente. As geadas de 1918 Ihes apresentaram positivas ao propiciar que comprassem terras a "preço de ocasião". Expandiram suas posses para Capivari, Iracemápolis e Limeira. Reunindo-se em 1932 na sociedade "Irmãos Ometto e Companhia", tocavam os negócios conjuntamente. Obtendo mais dinheiro ampliaram suas posses em Iracemápolis, modernizando o engenho que lá possuíam, dando início a Usina Iracema. Em 1936, põem para funcionar a Usina Costa Pinto, em Piracicaba, tendo como sócios, dentre outros, o industrial Mário Dedini. No ano de 1937 dão origem a uma nova formação societária, agora chamada "Companhia Industrial e Agrícola Ometto". ${ }^{29}$ Com duas usinas e uma destilaria, os irmãos resolveram terminar a sociedade e seguir caminhos paralelos, porém sempre no setor canavieiro, tendo a usina Iracema servido como "estágio" de formação e de "acumulação primitiva" para os filhos de Caterina. Pedro Ometto compra, então, em parceria com Mário Dedini e outros, 460 alqueires de terras no município de Barra Bonita. Neste local estabelecem, em 1943, a Usina da Barra. ${ }^{30}$ Nesse mesmo ano, Dovílio, filho de Pedro, casa-se com Ada, filha de Mário, interligando-se assim, agora também por consangüinidade, as famílias Ometto e Dedini. E quanto aos demais descendentes de Caterina? Em 1945 Luís funda a Usina Santa Cruz, em Américo Brasiliense. Em 1946 José inaugura a Usina São João, em Araras. Em 1947 Jerônimo funda a Usina Santa Lúcia, também em Araras. Os três Pedros deram seu pontapé inicial na escalada rumo ao topo antes da crise de 1929. Os três eram agricultores, comerciantes e industriais. Morganti, Biagi e Ometto viveram "in una ascesa senza soste" ${ }^{31}$ e com trabalho e às vezes uma boa dose de sorte, exemplificam a história de outros italianos (ou filhos de italianos nascidos em São Paulo) que adentraram na grande atividade canavieira paulista ainda antes da $2^{\text {a }}$ Guerra Mundial - e que nesse contexto se beneficiaram com os impactos desta sobre o setor. Não se pense, porém, que constituíram a "regra". Foram a "exceção da exceção".

No que diz respeito a espacialização canavieira, "no ano de 1940, existiam 33 usinas [...] duas áreas canavieiras consolidadas: Piracicaba e Sertãozinho/Ribeirão Preto. Nesse mesmo ano, a área de Araraquara já iniciava como a terceira em formação" ${ }^{32}$

MAPA 1: Territorialização da fabricação de açúcar - São Paulo/1936. ${ }^{33}$ 


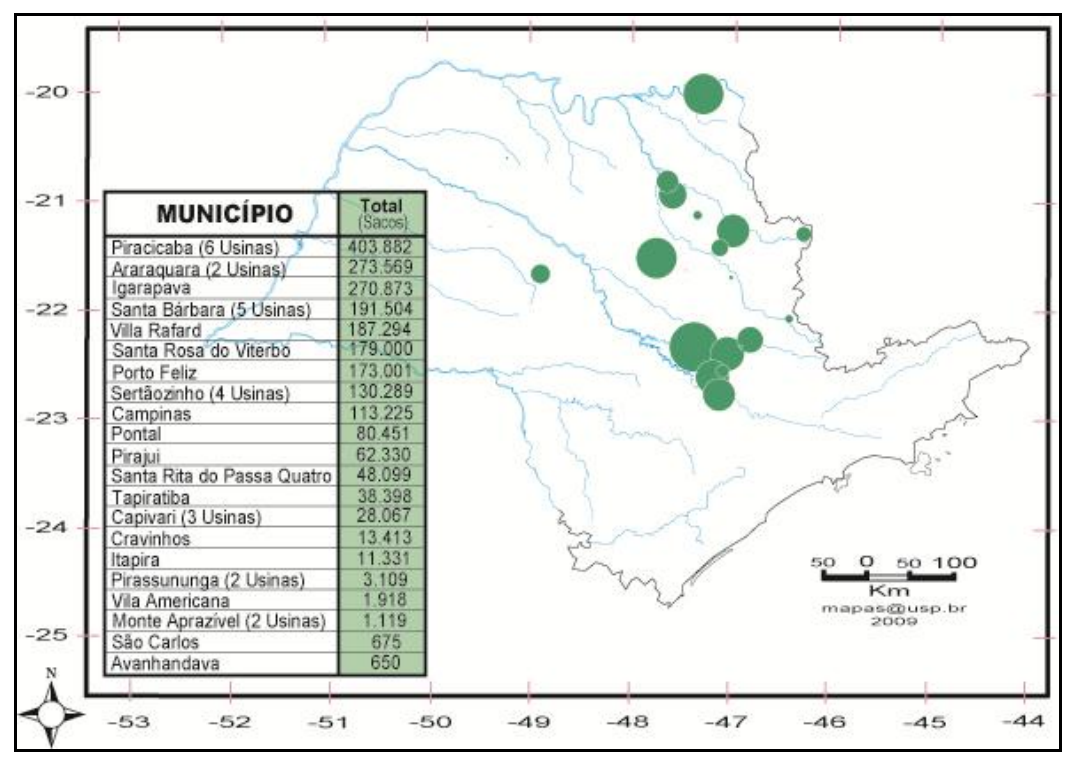

\section{De importador à exportador: 1945-1969}

Os anos de guerra foram de desabastecimento açucareiro em São Paulo (pois a mercadoria até então em grande parte proveniente de Pernambuco deixou de chegar à Santos). Foram anos também de inflexão alcooleira (faltava também gasolina e demais derivados de petróleo). Após uma longa "queda-de-braço" contra os planejadores do Instituto do Açúcar e do Álcool (I.A.A. representados, sobretudo, por seu presidente, o Sr. Barbosa Lima Sobrinho), liberou-se (parcialmente) a produção canavieira, açucareira, alcooleira e aguardenteira em São Paulo, obtendo-se ampliação considerável de sua cota de produção e autorizando-se a fundação de um certo número de novas usinas. É bom lembrar que desde a fundação do I.A.A. a produção fora restringida e era rigorosamente controlada. Nesse curto período de abertura houve uma "verdadeira 'corrida ao ouro' dos paulistas para registrar quotas de produção" ${ }^{34}$, havendo "motivos suficientes para se poder considerar a safra de 1947/48 como uma espécie de 'safra-marco' ", ${ }^{35}$ assinaladora de "grande salto quantitativo e qualitativo". ${ }^{36}$ Para se ter uma idéia do que estamos nos referindo, basta avaliar que o número de usinas existentes em São Paulo saltou de 40 na safra de 1945/46 para 79 na de 1950/51 ${ }^{37} \mathrm{Em}$ 1955/56 estas já eram 92 em operação. Em 1960 somavam 104. ${ }^{38} \mathrm{Na}$ virada da década de 1950 para $1960,35 \%$ do volume de açúcar exportado pelo país provinha do estado paulista. ${ }^{39}$ Havia se firmado no estado a "revolução industrial do açúcar e do álcool', que puxava a elevação dos índices de rendimentos agrícolas, ampliando sua área de cultivo e intensificando o patamar técnico aplicado na lavoura.

Com relação à territorialização canavieira no Estado, Fúlvio Morganti (filho de Pedro e na ocasião (1951) vice-presidente da "Associação dos Usineiros de São Paulo") preconizava que: "as novas fábricas deverão [deveriam] ser situadas em locais que não prejudiquem o fornecimento da matéria-prima e a natural expansão das usinas já em funcionamento". "40 Formaram-se os 
"bolsões canavieiros de Araras, Jaú e [Médio] Vale do Paranapanema, ao mesmo tempo em que se preparavam as condições necessárias para o estabelecimento da zona canavieira de Catanduva". ${ }^{41}$ Situar-se-ia esta última área a meio-caminho de Ribeirão Preto à São José do Rio Preto (na Araraquarense), assim de Ribeirão Preto à Novo Horizonte (na Douradense). As linhas de trem passavam a sofrer forte concorrência com capilaridade e agilidade dos "ônibus" e "caminhões", que se multiplicavam e ganhavam espaço na época. Estabelecia-se uma nova "ordem espacial' na atividade canavieira paulista e, por tabela, também na nacional.

\section{MAPA 2: Territorialização da fabricação de açúcar - São Paulo/1957. ${ }^{42}$}

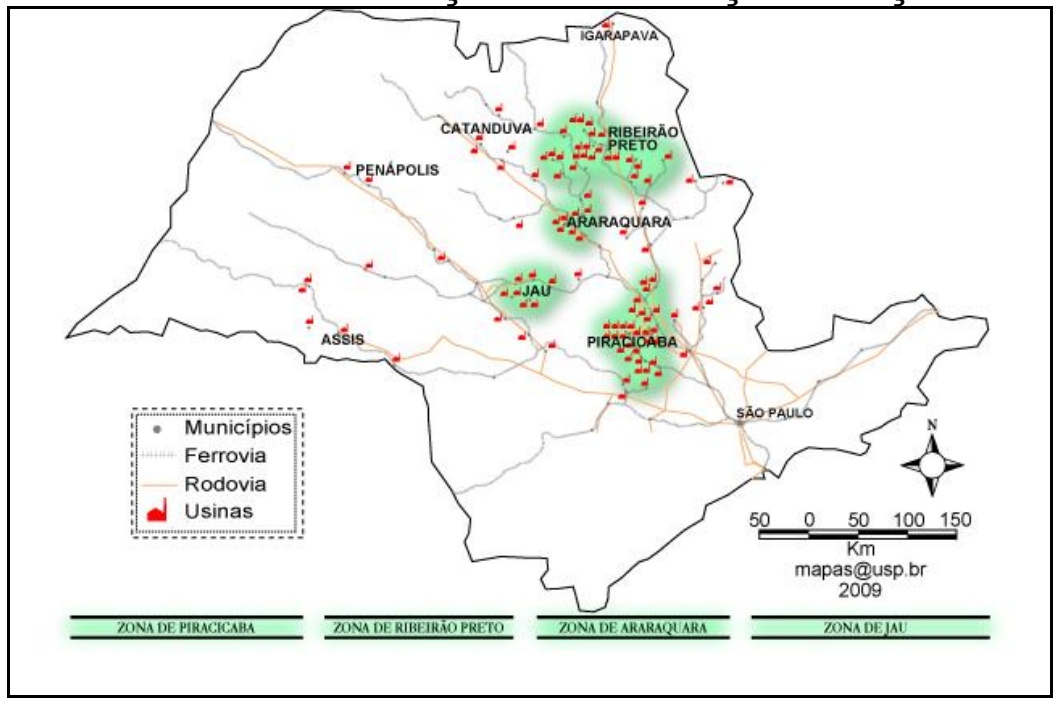

Passado um século após abandonar a condição de exportador de açúcar, São Paulo retoma essa posição, tornado-se - em boa parte graças à evolução que se promoveu na parte industrial da produção - na maior "potência" açucareira do Brasil. Desde 1953/54 havia suplantado definitivamente Pernambuco em termos de moagem de cana e produção de açúcar. Os anos 1950 e a primeira metade dos 1960 foram de bonança e prosperidade aos usineiros - quebras e falências foram poucas e pontuais. Em 1959 surgiu a Copersucar para beneficiar os interesses das 32 usinas a ela cooperedas. Em 1963 o IAA organizou o "Programa Diretivo para a Política Açucareira e Alcooleira", que posteriormente converteu-se no "Plano de Expansão da Indústria Açucareira Nacional'. O objetivo principal era ampliar a produção açucareira do país, dobrando sua produção dentro de um intervalo de apenas oito anos (19631971). Tal política acarretou num aumento de $98,9 \%$ na cota estadual paulista, o que veio acompanhado da autorização para a instalação de novas plantas industriais, iniciadas a partir de 1964. 43 Também em 1964 deu-se a intervenção do IBC ("Instituto Brasileiro do Café") através do GERCA - "Grupo Executivo de Racionalização da Cafeicultura" - que com financiamentos Banco do Brasil promoveu a substituição "do verde escuro dos cafezais pelo verde claro dos canaviais". ${ }^{44}$ 
O incremento vivenciado na produção açucareira no Pós-Guerra por meio de progresso técnico e expansão territorial tinha sido tamanho, que o otimismo dos produtores - e o erro dos planejadores oficiais - ocasionaram uma "supersafra" no ano de $1966{ }^{45}$, contribuindo para que os preços internacionais despencassem ainda mais. As medidas de 1963 e 1964 aumentaram a produção estadual das quase 27.000 .000 sacos de 60 quilos de 1965 para as mais de 42.000.000 no ano seguinte. Ainda nesse ano (1965) uma parte significativa dos canaviais deixou de ser colhida (equivalente à 13.000.000 sacos) devido ao "excesso" de matéria-prima nos campos. ${ }^{46}$ Para agravar a situação, os "estoques reguladores de preços já estavam sobremaneira elevados" ${ }^{47}$ e nem mesmo utilizando-se da "válvula de escape" que constituíase a prática de "desviar" parte substancial dos canaviais para a fabricação de álcool conseguiu-se impedir a crise que assolou o setor. Em 1966 o Estado passava por sua primeira grande crise de superprodução. Para se ter uma idéia, ao final da década de 1960 as três maiores unidades produtoras de sacos de açúcar no Estado (safra 1969/70) - usinas Da Barra (2.200.000 sacos), São Martinho (1.750.000 sacos) e São João (1.150.000 sacos); todas pertencentes a "Omettos" (na geração dos filhos e sobrinhos de Pedro) fabricaram, juntas, apenas $10 \%$ menos açúcar do que haviam produzido todas as 42 usinas em funcionamento na referida "safra-marco" de 1947/48. Em apenas 21 anos (1948-1969) três usinas passaram a dar conta de produzir quase a mesma quantidade de açúcar que todo o Estado produzia pouco tempo antes! Donde conclui-se que o plano de produzir muito mais tinha dado certo; porém o de vender muito mais não gozava do mesmo êxito.

\section{De Leste à Oeste: 1971-2011}

Para "resolver" a situação de descompasso entre oferta e demanda do produto veio a fase da "racionalização" (e concentração) do setor. O "Programa de Racionalização da Agroindústria Canavieira", concomitantemente com o "Programa Nacional de Melhoramento da Cana-de-açúcar" (ambos de 1971 e inseridos no "Plano Básico de Desenvolvimento Científico e Tecnológico" do Governo Federal) acarretou numa importante seqüência de fusões, incorporações e relocalizações das unidades fabris. ${ }^{48} \mathrm{O}$ que se intencionava era substituir o "empirismo que prevaleceu na montagem e localização das fábricas açucareiras [até então pela] racionalização técnico-econômica que a nova sistemática estabelece [possibilitando] redução de custos operacionais". 49 A estratégia consistia em concentrar a produção para concertar a superprodução - o que é um tanto questionável. Os recursos empregados no financiamento dessa concentração advinham do "Fundo Especial de Exportação" (estabelecido em 1965) e era fruto dos "superávits" obtidos pelo governo diante de seu monopólio praticado na exportação do açúcar.

A estratégia parecia funcionar e em 1972 o país havia se tornado o maior exportador mundial açúcar, cabendo a São Paulo fatia importante nesse comércio. A Copersucar ia bem e em 1973 comprou a marca "União" de açúcar (fundada por Pedro Morganti em 1910). Em 1974 a Copersucar comprou as "Usinas Brasileiras de Açúcar S.A.", fruto esta da incorporação (transitória e de 
curta duração) das usinas do grupo Morganti e das da "Societé Française des Sucrérie Brésiliennes" pela família Silva Gordo. Entre 1969 e 1974 as exportações brasileiras triplicaram, sendo São Paulo, de longe, o maior produtor e exportador da nação. ${ }^{50}$ Algumas das usinas paulistas agigantavamse comprando e incorporando cotas de outras empresas, sobretudo as de algumas empresas menores localizadas em estados pouco canavieiros ou em decadência canavieira - como era o caso de Minas Gerais, Rio de Janeiro, Goiás e Mato Grosso. As grandes compravam também as cotas (e com isso o direito de funcionamento) também de outras usinas paulistas, interessandoIhes sobretudo possíveis usinas vizinhas mal administradas - a posse das terras e a monopolização dos arrendamentos eram, nesses casos, dois pontos centrais. Após a intensa ampliação do número de fábricas açucareiras em operação no Estado ocorrida entre as décadas de 1890 e 1960, pela primeira vez em décadas essa quantia tendeu a cair:

TABELA 1: Variação no número de usinas de açúcar - São Paulo/19401975. ${ }^{51}$

\begin{tabular}{|c|c|c|c|}
\hline PERIODO & Abertura & Fechamento & "Saldo \\
\hline Década de 1940 & +49 & -03 & +46 \\
\hline Década de 1950 & +21 & -05 & +16 \\
\hline Década de 1960 & +04 & -05 & -01 \\
\hline Década de 1970 (até 1975) & +04 & -23 & -19 \\
\hline
\end{tabular}

Nesse momento de "relocalização" e correção do "empirismo" predominante no que se referia à localização das plantas industriais, o I.A.A. enxergava no território paulista como uma composição de cinco diferentes regiões canavieiras: as de Piracicaba, Araraquara, Ribeirão Preto/Sertãozinho, Jaú e Vale do Paranapanema. ${ }^{52}$

Nesse momento os engenhos de açucares mascavos e rapaduras já haviam sido dizimados e os pequenos produtores de aguardente também passavam por uma situação encurraladora. Em 1959 a "Cia. Muller de Bebidas (51)", de Pirassununga, iniciava seu processo de expansão que Ihe renderia a liderança regional e posteriormente nacional no comércio de aguardente no Brasil. Outra grande fusão no setor aguardenteiro foi o das "Indústrias Reunidas de Bebidas Tatuzinho". Fundada na cidade de Rio Claro em 1970, pela fusão das tradicionais marcas "Tatuzinho" e " 3 Fazendas", cinco anos mais tarde a empresa se reforçaria ainda mais com a compra da marca "Velho Barreiro", alcançando um nível de concentração (econômica, e não apenas alcoólica) muito superior aos padrões médios que se verificavam no Estado. Pode-se dizer que a cachaça estadual decaiu de qualidade e que os produtores menores entraram em séria dificuldade concorrencial (ambas as afirmações são facilmente comprováveis).

Nova grave crise açucareira foi vivenciada em 1974, fato este que se associou às reviravoltas políticas e econômicas ocorridas nos países do Oriente Médio, ocasionando na criação do Proálcool em 1975. Entre esse ano e 1980, o que 
se passou no Estado de São Paulo foi um reforço das tradicionais empresas açucareiras via estímulos do Proálcool. Fortaleceram-se as "tradicionais áreas canavieiras paulistas de Piracicaba - na Depressão Periférica Sertãozinho/Ribeirão Preto, Araraquara, Jaú e Vale do Paranapanema - no Alto e Médio Planalto Ocidental Paulista". ${ }^{53}$ Em 1979 o programa federal mudou um pouco de faceta e após 1980, de acordo com o planejamento estadual estabelecido pelo "Plano de Desenvolvimento do Oeste do Estado de São Paulo" (PRO-OESTE), que pôs em prática o "Programa de Expansão da Canavicultura para produção de Combustível do Estado de São Paulo" (PROCANA), os canaviais paulistas tomaram novos direcionamentos. ${ }^{54} \mathrm{O}$ estabelecimento de "áreas prioritárias" pelo PROCANA conferiu às "Regiões Administrativas" de Presidente Prudente, Araçatuba, Bauru, assim como ao oeste da de São José do Rio Preto, "status" diferenciado, privilegiado. Pretendia-se orientar o fluxo de recursos financeiros oriundos do PROÁLCOOL, utilizando-os como "instrumentos básicos para 0 desenvolvimento da região oeste" ${ }^{55}$ com ênfase no consórcio cana-boi. 56 Visava-se eliminar/amenizar as "disparidades regionais". Muitos pecuaristas se uniram em associações locais para elaborar e fazer aprovar projetos de financiamento junto ao Governo Federal, beneficiando-se dessa forma da política territorial estabelecida no nível estadual. Assim, após cerca de dez anos ( $\pm 1972-1982)$, voltou a se ampliar o número de usinas em funcionamento no Estado.

MAPA 3: Priorização política do "Oeste" para a expansão alcooleira - São Paulo/1980. ${ }^{57}$

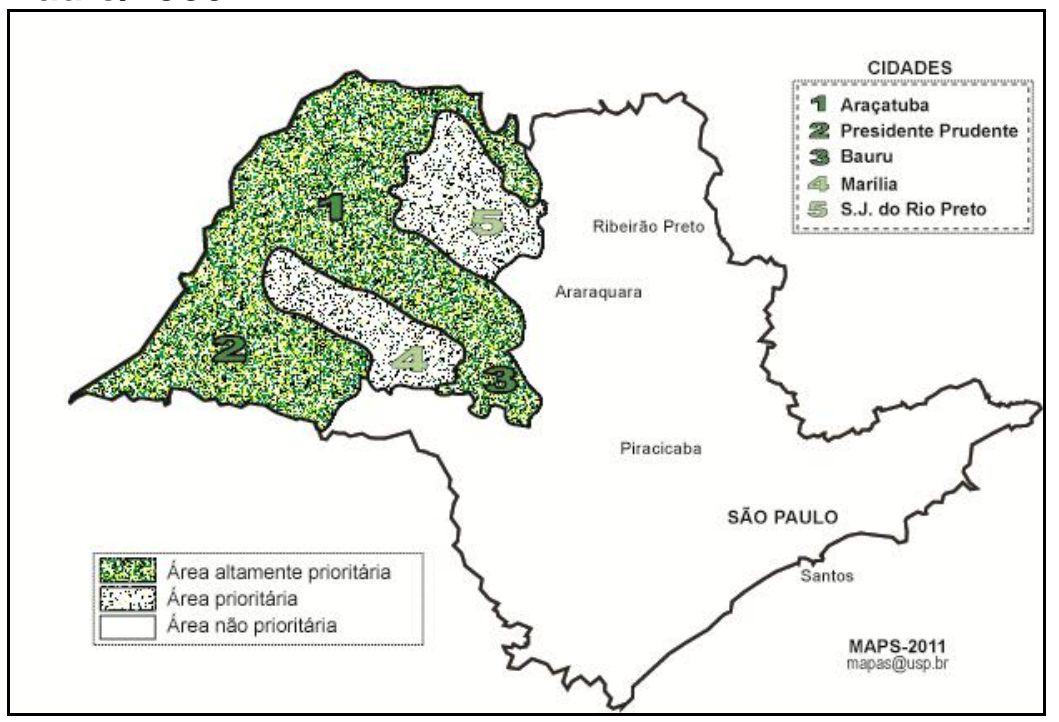

A década de 1980 iniciou bem para o setor - este era considerado "estratégico" pelo Governo Federal e por isso era altamente subsidiado. Porém terminou mal a década iniciada com tanta energia. O fim do "Regime Militar" e a "Nova Constituição" de 1988, assim como algumas alterações de cunho macroeconômico de escala global fizeram da transição dos 1980 para os 1990 anos difíceis para o setor, que adentrou numa década de falências e fusões, até chegarmos à virada do milênio. Com a entrada dos 2000 a cana tomou novo 
impulso, e este "novo impulso" foi certamente o maior de sua história. Apenas nos oito anos de governo Lula (2003-2011) a produção canavieira nacional dobrou. ${ }^{58} \mathrm{O}$ "Oeste" de São Paulo firmou-se com isso como mais uma das regiões canavieiras do Brasil, dando origem ao que estamos chamando de "Macro-Região Canavieira Paulista". Se o PRO-OESTE havia plantado uma semente e estabelecido um marco definitivo para a expansão canavieira para o "oeste" de São Paulo, esta veio a germinar com a retomada dos financiamentos governamentais (sobretudo via "BNDES") e com a chegada maciça de novos investimentos internacionais. O número de usinas voltou a crescer no Estado, sobretudo em sua porção ocidental.

Para investigar esse último momento da expansão canavieira em São Paulo propomos essa idéia da "Macro-Região Canavieira Paulista", pela qual todas as regiões canavieiras historicamente constituídas (o Quadrilátero, Piracicaba, Ribeirão Preto/Sertãozinho, Araraquara, Jaú, Vale do Paranapanema, Araras e Catanduva) se unem às novas zonas de São José do Rio Preto, Araçatuba e Presidente Prudente. Praticamente deixam de haver relevantes manchas de descontinuidade canavieira desde o "sopé da Mantiqueira" até as "barrancas do Paraná" (Além da "Serra do Mar/Paranapiacaba" e dos vales "do Paraíba" e "do Ribeira" - ambos próximos ao litoral - apenas a área de Marília e alredores configura-se como local de resistência espacial à entrada da cana). Frisa-se que seguem existindo peculiaridades espaciais e diferentes "papéis" desempenhados dentro da "divisão territorial do trabalho" e no "circuito produtivo" canavieiro do Estado. No entanto, as "regiões" tornaram-se "subregiões", e agora integram uma única "Macro-Região".

MAPA 4 - Superposição das zonas canavieiras paulistas - 1975 / 1990 e $1990 / 2005^{5}$

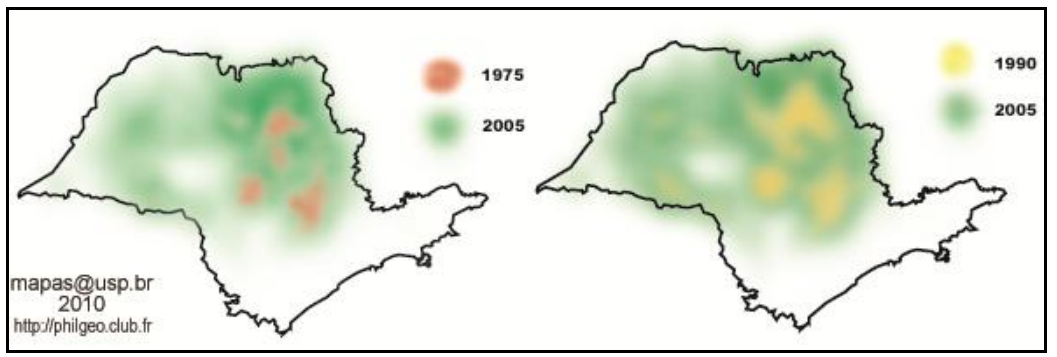

\section{Conclusão}

Após um retrospecto histórico-geográfico da canavicultura paulista, sugere-se uma proposta de regionalização para ser discutida com os colegas e pesquisadores de temáticas afins; a fim de alcançar um melhor entendimento da espacialização dessa cultura no Estado de São Paulo. 
1 Doutorando em Geografia Humana pelo D.G./F.F.L.C.H./USP. Aproveito para agradecer à Prof ${ }^{a}$ - $r^{a}$ Rosa Ester Rossini pela orientação, e à FAPESP pelo apoio financeiro.

2 PETRONE, 1968, p. 10. (Essa localização coincide aproximadamente com lugar onde hoje se encontram o Museu Casa do Bandeirante e a própria Cidade Universitária de São Paulo USP).

${ }^{3}$ FRAGINALS, 1989 e ABBOTT, 2010.

${ }^{4}$ Apud. DEAN, 1977, p. 30.

${ }^{5}$ Apud. BRUNO, 1966, p. 114.

${ }^{6}$ CANDIDO, 2003, pp. 112-113.

7 PETRONE, 1968.

${ }^{8}$ D'ALINCOURT, 2006, p. 31-33.

${ }^{9}$ Em seguida estava a região do "Vale do Paraíba", que contava com $38 \%$ desses em 1798, e apenas 15\% em 1828. MARCÍLIO, 2000, p. 110.

${ }^{10}$ PETRONE, 1968, pp. 176-177 e p. 151.

${ }^{11}$ ARAÚJO FILHO, 1969, pp. 52-53.

12 QUEDA, 1972 , p. 80.

13 Villa-Raffard foi fundada pela empresa açucareira como uma mistura de "vila industrial" e "colônia agrícola", na qual todos os moradores possuíam alguma ligação profissional com o Engenho. Hoje é um município.

14 PICARD, 1903, p. 42.

15 BRAY, 1989, pp. 3-4.

${ }^{16}$ BRAY, 1989, pp. 129 e 136.

17 QUEDA, 1972, pp. 2-3.

18 BOLETIM DE AGRICULTURA, 1903, pp.562, 578 e 583. Apud. BRAY, 1989, p. 92 e pp. 9697.

19 SAWIER, 1905, p. 64.

20 Do Tupi: arrebentavam, saltavam.

${ }^{21}$ GAETA, 1997, p. 54

22 D.O.U. 9.792 de 06 de julho de 1913. Disponível em http://www.jusbrasil.com.br/diarios/1878113/dou-secao-1-06-07-1913-pg-54/pdfView

${ }^{23}$ A fusão da COSta Pinto com a usina SANta Bárbara deu origem, em 1987, à $\underline{\text { COS } / S A N}=$ COSAN, atual "raizen".

24 BRAY, 1989, p. 159.

${ }^{25}$ Ralph Mennucci Giesbrecht, in: http://www.estacoesferroviarias.com.br/i/itaquere.htm, acesso realizado em 11/11/11, as 11:11:11 am.

${ }^{26}$ VIZIOLI, 1927, p. 19.

27 SZMRECSÁNYI e VEIGA FILHO, 1999 e SZMRECSÁNYI, 1988.

28 SAMPAIO, 2010.

${ }^{29}$ Gordinho apud. CAMPAGNOL, 2008, pp. 219-220.

${ }^{30}$ Hoje a maior em operação no mundo.

${ }^{31}$ ORNELLAS, 1967, p. 125.

${ }^{32}$ BRAY e FERREIRA, 1984.

33 Elaboração própria a partir de: BRAY, 1989, p. 155.

${ }^{34}$ RAMOS, 1998, pp. 107-108.

35 SAMPAIO, 2010, p. 62.

${ }^{36}$ QUEDA, 1972, p. 100.

37 BRAY, 1989, p. 164. 
39 RAMOS, 1998, p. 122.

40 Apud. BRAY, 1985, p. 102.

41 SAMPAIO, 2010, pp. 62-63.

42 Elaboração própria a partir de: CAMPAGNOL, 2008, p. 210.

43 ANDRADE NETO, 1990, p. 253.

44 Idéia tomada de LEITE, 2003, p. 23.

45 SAMPAIO, 2010.

${ }^{46}$ BRAY e RUAS, 1995, p. 314 e SZMRECSÁNYI, 1979, p. 272.

${ }^{47}$ SZMRECSÁNYI, 1979, p. 271.

${ }^{48}$ SZMRECSÁNYI, 1979, p. 304.

${ }^{49}$ CARNEIRO in: IAA, Revista Brasil Açucareiro, nov. de 1971, p. 11.

50 OLALDE apud. THOMAZ JÚNIOR, 2002, p. 91.

${ }^{51}$ Fonte: IAA apud. BRAY e FERREIRA, 1983, p. 63.

${ }^{52}$ Ver BRAY, FERREIRA e RUAS, 2000, p. 86.

${ }^{53}$ BRAY e FERREIRA, 1983.

${ }^{54}$ Seria São Paulo igual ao Paraná: um Estado com três "Oestes" assincrônicos?

${ }^{55}$ BRAY e FERREIRA, 1983.

${ }^{56}$ REGO, 1990 e BINI, 2009.

${ }^{57}$ Elaboração própria a partir de: BRAY, FERREIRA e RUAS, 2000, p. 88.

${ }^{58}$ Fonte: MAPA e UNICA.

${ }^{59}$ Elaboração própria a partir de: Censo Agropecuário (1975) e PAM/IBGE (1990 e 2005).

\section{Referências Bibliográficas:}

ABBOTT, Elizabeth. Haiti's Revolution Fueled the Rise of Big Sugar in Cuba and Louisiana. Overlook Press, 2010. Disponível em: http://repeatingislands.com/2010/04/12/haitis-revolutionfueled-the-rise-of-big-sugar-in-cuba-and-louisiana/ , acesso realizado em 10/06/2011.

ANDRADE NETO, Joaquim Correia Xavier de. O Estado e a agroindústria canavieira do Nordeste Oriental: Modernização e Proletarização. São Paulo: Tese de Doutorado (DG/FFLCHUSP), 1990.

ARAÚJO FILHO, José Ribeiro de. "O café, riqueza paulista". Boletim Paulista de Geografia. Especial 40 anos. São Paulo: Associação dos Geógrafos Brasileiros, Seção São Paulo, n. 68, p.51-124, 1969.

BINI, Danton Leonel de Camargo. Mudanças históricas e implicações sócio-espaciais na composição das atividades agropecuárias hegemônicas na região de Araçatuba (SP). São Paulo: Dissertação de Mestrado (DG/FFLCH-USP), 2009.

BRAY, Silvio Carlos. "As políticas do Instituto do Açúcar e do Álcool e do Programa Nacional do Álcool e suas influências na área açucareira-alcooleira de Catanduva”. Rio Claro: Boletim de Geografia Teorética, 10(20) pp. 99-123, 1985. 
BRAY, Sílvio Carlos. A formação do capital na agroindústria açucareira de São Paulo: revisão dos paradígmas tradicionais. Rio Claro: Tese de Livre Docência (IGCE/UNESP), 1989.

BRAY Silvio Carlos e FERREIRA, Enéas Rente. "As agro-indústrias e a formação do setor canavieiro de Araras". Rio Claro: Boletim de Geografia Teorética, 13(25) pp. 57-68, 1983.

BRAY, Silvio Carlos e FERREIRA, Enéas Rente. "As influências do Proálcool e do Pró-Oeste nas transformações das áreas canavieiras do Estado de São Paulo". Rio Claro: Boletim de Geografia Teorética, v. 9, no. 17-18, p. 101-113, out. 1984.

BRAY Silvio Carlos e RUAS, Davi Guilherme Gaspar. "Crescimento e consolidação das usinas de açúcar no estado de São Paulo - 1950 a 1974”. Rio Claro: Boletim de Geografia Teorética. 25(49-50) pp. 301-326, 1995.

BRAY Silvio Carlos, e FERREIRA, Enéas Rente e RUAS, Davi Guilherme Gaspar. As políticas da agroindústria canavieira e o Proálcool no Brasil. Marília: Editora da UNESP, 2000.

BRUNO, Ernani Silva. Viagem ao País dos Paulistas - Ensaio sobre a ocupação da área vicentina e a formação de sua economia e de sua sociedade nos tempos coloniais. Rio de Janeiro, José Olympio, 1966, 1ª Edição.

CAMPAGNOL, Gabriela. Usinas de açúcar: habitação e patrimônio industrial. São Carlos: Tese de Doutorado (IAU/EESC-USP), 2008.

CANDIDO, Antonio. Os Parceiros do Rio Bonito: Estudo sobre o Caipira Paulista e a transformação de seus meios de vida. São Paulo: Duas Cidades, 2003.

D'ALINCOURT, Luís. Memória sobre a Viagem do Porto de Santos à Cidade de Cuiabá. Brasília: Senado Federal, 2006.

DEAN, Warren. Rio Claro um Sistema Brasileiro de Grande Lavoura 1820-1920. Rio de Janeiro: Paz e Terra, 1977.

FRAGINALS, Manuel Moreno. O Engenho - Volume I. São Paulo: Editora da UNESP, 1989.

GAETA, Maria Aparecida Junqueira da Veiga. A flor do café e o caldo da cana - os caminhos de Sinhá e Quito Junqueira. Uberaba: Editora Vitória LTDA, 1997.

LEITE, Silvia Ibiraci de Souza. A usina São Domingos: os canaviais, a fábrica e os trabalhadores (1952-1973). São Paulo: Annablume, 2003.

MARCÍLIO, Maria Luiza. Crescimento demográfico e evolução agrária paulista: 1700-1836. São Paulo: Hucitec/Edusp, 2000.

ORNELLAS, Manoelito. Um bandeirante da Toscana (Pedro Morganti na lavoura e na indústria açucareira de São Paulo). São Paulo: EDART, 1967. 
PETRONE, Maria Thereza Schorer. Lavoura canavieira em São Paulo: expansão e declínio (1765-1851). São Paulo: Difusão Européia do Livro, 1968.

PICARD, J. Usinas Açucareiras de Piracicaba, Villa-Raffard, Porto-Feliz, Lorena e Cupim. Missão de Inspeção do Senhor J. Picard, Engenheiro, de I de março a 15 de julho de 1903. Tradução: Maria da Glória Porto Kok e Alberto Alexandre Martins; Revisão Técnica: Oriowaldo Queda e Tamás Szmrecsányi. Estudos Rurais 14. São Paulo: Editora Hucitec/Editora da Unicamp, 1996.

QUEDA, Oriowaldo. A intervenção do estado e a agroindústria açucareira paulista. Piracicaba: Tese de Doutorado (ESALQ/USP), 1972.

RAMOS, Pedro. Agroindústria canavieira e propriedade fundiária no Brasil. São Paulo: Hucitec, 1998.

REGO, M. T. R. Proálcool na região de Araçatuba: o doce fel do binômio cana-boi. São Paulo: Tese de Doutorado/USP, 1990

SAMPAIO, Mateus de Almeida Prado. Aceleração do tempo e encurtamento das distâncias - o histórico papel das técnicas no processo de interiorização e modernização da canavicultura paulista: séculos XVI a XXI. Dissertação de Mestrado, DG/FFLCH-USP, 2010. Disponível em http://www.teses.usp.br/teses/disponiveis/8/8136/tde-22122010-143613/es.php

SAWYER, Frederic H. Relatório apresentado à Sociedade Paulista de Agricultura, Commércio e Indústria, 1905. São Paulo, Typographia Brasil, 1905.

SECRETARIA DE AGRICULTURA E ABASTECIMENTO/GOVERNO DO ESTADO DE SÃO PAULO. Bases para um Plano de Desenvolvimento do Oeste do Estado de São Paulo - ProOeste. São Paulo: SAA, 1980.

SZMRECSÁNYI, Tamás József Márton Károly. O planejamento da agroindústria canavieira do Brasil. Campinas, Hucitec - Unicamp, 1979.

SZMRECSÁNYI, Tamás József Márton Károly. "1914-1939: Crescimento e crise da agroindústria açucareira no Brasil'. In: Revista Brasileira de Ciências Sociais, junho/1988. Disponível em http://www.anpocs.org.br/portal/publicacoes/rbcs $00 \quad 07 /$ rbcs07 02.htm

SZMRECSÁNYI, Tamás József Márton Károly e VEIGA FILHO, Alceu de Arruda. "O ressurgimento da lavoura canavieira em São Paulo na Primeira República, 1890-1930". In: Travesía, № 2, primer semestre de 1999, pp. 67-81. Disponível em http://www.travesiaunt.com.ar/pdf/travesia2 4.pdf

THOMAZ JR., Antonio. Por Trás dos Canaviais, os Nós da Cana. São Paulo: Annablume/FAPESP, 2002. 
VIZIOLI, José. A indústria assucareira no estado de São Paulo - a sua situação actual. São Paulo: Secretaria da Agricultura, Commércio e Obras Públicas do Estado de São Paulo Directoria de Publicidade, 1927.

\section{Periódicos:}

Diário Oficial da União (DOU), disponível em http://www.jusbrasil.com.br/noticias

“Revista Brasil Açucareiro”, Rio de Janeiro, I.A.A. - várias edições.

\section{Sites:}

Estações Ferroviárias do Brasil, in: http://www.estacoesferroviarias.com.br

Ministério da Agricultura, Pecuária e Abastecimento (MAPA), in http://www.agricultura.gov.br/

União da Indústria de Cana-de-Açúcar (UNICA)

in: http://www.unica.com.br/ 